\title{
Hubungan Infestasi Ctenocephalides felis dan Xenopsylla cheopis dengan Perawatan Kucing Rumah (Felis catus) di Kabupaten Banjarnegara
}

\section{The Correlation Between Infestation of Ctenochepalides felis and Xenopsylla cheopis with Domestic Cats (Felis catus) Nurtureship in Banjarnegara Regency}

\author{
Eva Lestari*, Rahmawati, Dewi Puspita Ningsih \\ Balai Penelitian dan Pengembangan Kesehatan Banjarnegara, Badan Litbang Kesehatan, \\ Kementerian Kesehatan RI \\ Jalan Selamanik No. 16A Banjarnegara, Jawa Tengah, Indonesia \\ *E_mail: evalestari.epid@gmail.com
}

Received date: 04-05-2020, Revised date: 05-08-2020, Accepted date: 11-11-2020

\begin{abstract}
ABSTRAK
Pinjal sebagai ektoparasit hidup pada permukaan tubuh kucing. Jenis pinjal yang sering dijumpai yaitu Ctenocephalides felis. Keberadaan pinjal kucing dapat dipengaruhi oleh cara perawatan kucing. Pinjal kucing berpotensi menularkan penyakit pada manusia. Tujuan penelitian untuk memperoleh informasi infestasi pinjal pada kucing rumah dan mengidentifikasi faktor yang mempengaruhi keberadaan pinjal tersebut. Jenis penelitian observasional analitik dengan pendekatan cross-sectional. Penelitian dilakukan di Kabupaten Banjarnegara pada Bulan Juni-November 2019, sebanyak 100 ekor kucing rumah (Felis catus) diperiksa keberadaan pinjalnya. Wawancara dilakukan terhadap pemilik kucing untuk memperoleh informasi cara perawatan kucing. Data dianalisis secara deskriptif dan statistik menggunakan uji Mann-Whitney dan Chi-Square. Hasil penelitian menunjukkan persentase kucing positif pinjal lebih besar pada kucing dirawat (82\%) daripada kucing tidak dirawat (68\%). Spesies pinjal kucing yang ditemukan yaitu C. felis $(99,8 \%)$ dan Xenopsylla cheopis $(0,2 \%)$. Berdasarkan analisis statistik diketahui bahwa tidak ada perbedaan signifikan antara jumlah pinjal pada kucing dirawat dan tidak dirawat $(\mathrm{p}=0,072)$. Uji korelasi menunjukkan adanya hubungan antara frekuensi kucing dimandikan menggunakan shampoo khusus kucing dengan keberadaan pinjal kucing $(\mathrm{p}=0,001)$, sedangkan kebiasaan kucing dikandangkan $(\mathrm{p}=0,331)$, pemberian obat kutu/pinjal $(\mathrm{p}=0,177)$, dan jumlah kucing yang dipelihara $(\mathrm{p}=0,884)$ tidak ada hubungan signifikan dengan keberadaan pinjal pada kucing.
\end{abstract}

Kata kunci: pinjal, kucing rumah, Ctenocephalides felis, perawatan kucing

\begin{abstract}
Fleas as ectoparasites live on the cat's body surface. Ctenocephalides felis is one of the type fleas that often found in cats. The presence of fleas in cats can be influenced by the way the cat is groomed. Fleas in cats have the potential to transmit the disease to a human. The purpose of this study was to determine fleas infestation in domestic cats and determine factors that affect the presence of fleas in cats. This study was observational analytic with a cross-sectional approach and conducted in Banjarnegara Regency on June-November 2019. Total of 100 domestic cats (Felis catus) were checked for fleas. Interviews were conducted with cat owners to obtain information on how to groom cats. Data were analyzed descriptively and statistically using MannWhitney and Chi-Square Test. The results showed a greater percentage of fleas positive in groomed cats (82\%) than ungroomed cats (68\%). Fleas species found in cats were C. felis (99.8\%) and Xenopsylla cheopis $(0.2 \%)$. Based on statistical analysis there was no difference amount of fleas between groomed cats and ungroomed ( $p=$ 0.072). A correlation test showed a relationship between the frequency of cats being bathed with cat-specific shampoo and the presence of fleas in cats $(p=0.001)$. While the habits of cats caging $(p=0.331)$, the supply of ectoparasiticides $(p=0.177)$, and the number of cats kept $(p=0.884)$ showed no significant relationship with the presence of fleas in cats.
\end{abstract}

Keywords: fleas, domestic cats, Ctenocephalides felis, cats nurture 


\section{PENDAHULUAN}

Pinjal merupakan ektoparasit pada kelompok Mamalia dan Aves, hidup tidak permanen pada binatang dan manusia., ${ }^{1,2}$ Peranan pinjal dalam kesehatan diantaranya sebagai ektoparasit, vektor penyakit, dan hospes perantara. ${ }^{3,4}$ Pinjal sebagai serangga ektoparasit hidup pada permukaan tubuh inangnya. Inang dapat berupa kucing, anjing, tikus, kelinci, unggas/ayam, kelelawar dan hewan berkantung (marsupialia). ${ }^{1,4}$

Pinjal berkembangbiak dengan metamorfosis sempurna, yaitu berawal dari telur menjadi larva, pupa, kemudian menjadi dewasa. ${ }^{4,5}$ Pinjal betina mengeluarkan telur sekitar 25-40 butir per hari. Fase larva terdiri atas tiga instar yang berlangsung selama 2-3 minggu. Perkembangan siklus hidup pinjal tergantung pada kondisi lingkungan. Suhu yang tinggi akan membuat waktu perkembangbiakan pinjal lebih panjang. ${ }^{5}$

Dari 2500 spesies pinjal yang ada, Ctenocephalides felis, C. canis, dan Pulex irritans merupakan pinjal yang penyebarannya paling luas di dunia. ${ }^{6}$ Jenis pinjal yang sering dijumpai sebagai ektoparasit dan menimbulkan masalah kesehatan di Indonesia yaitu Xenopsylla cheopis, $P$. irritans, $C$. felis dan $C$. canis. $^{1}$ Beberapa penyakit yang ditularkan pinjal yaitu Flea Allergic Dermatitis (FAD), Dipylidiasis dan Rickettsiosis. ${ }^{7-10}$ Pinjal dapat menimbulkan gangguan akibat gigitannya sehingga menyebabkan iritasi kulit dan dermatitis pada manusia dan hewan. ${ }^{1,3,11}$ Pinjal dapat menyebabkan pruritus pada anjing dan kucing serta dapat menjadi vektor yang potensial untuk penyakit zoonosis. ${ }^{12}$ Rickettsiosis merupakan salah satu penyakit zoonosis yang ditularkan oleh pinjal. Ctenocephalides felis dapat menularkan penyakit yang disebabkan Rickettsia felis dan Bartonella sp. ${ }^{12}$ sedangkan $X$. cheopis merupakan vektor utama murine typhus dan pes yang biasanya dijumpai pada tikus. ${ }^{13}$

Kejadian Rickettsiosis di Indonesia sudah terlaporkan sejak awal tahun 1900-an di wilayah Sumatera, Jawa, hingga Papua. ${ }^{14}$ Indonesia merupakan salah satu wilayah endemis Rickettsiosis. Antibodi R. typhi pada manusia telah dilaporkan di beberapa wilayah di Indonesia, seperti Malang, Jakarta, Semarang. ${ }^{15-17}$ Infeksi $R$. felis pada X. cheopis juga ditemukan di Indonesia. ${ }^{18}$

Beberapa penelitian telah melaporkan adanya Rickettsia pada kucing. Penelitian Capelli et al tahun 2009 di Italia melaporkan sebanyak $11,9 \%$ C. felis yang terdiri atas 13 ekor pinjal dari kucing $(17,6 \%)$ dan 25 ekor pinjal dari anjing $(10,2 \%)$ menunjukkan hasil positif $R$. felis. ${ }^{19}$ Hasil penelitian Maina et al menunjukkan dari 597 spesimen pinjal yang dikoleksi dari opossum dan kucing, 37,2\% dinyatakan positif Rickettsia. ${ }^{10}$

Kucing rumah (Felis catus) merupakan jenis kucing yang banyak dijumpai di lingkungan permukiman penduduk dan tempat-tempat umum seperti pasar, rumah makan, dan tempat lain. Kucing jenis ini masih sering ditemukan sebagai hewan peliharaan. Jika kebersihan kucing kurang diperhatikan akan banyak dijumpai pinjal pada tubuh kucing. ${ }^{8}$ Ctenocephalides felis merupakan jenis pinjal yang sering dijumpai pada kucing dan anjing. ${ }^{20,21}$ Ciri-ciri $C$. felis di antaranya adalah nampaknya pronotal comb dan genal comb dengan duri yang berjumlah lima atau lebih, mata terlihat jelas, duri pertama dan kedua pada genal comb mempunyai ukuran yang sama panjang. ${ }^{22,7}$

Keberadaan pinjal pada kucing dapat dipengaruhi oleh cara perawatan kucing dan kondisi lingkungan sekitar. ${ }^{23-25}$ Larva pinjal dapat bertahan hidup pada kelembaban nisbi > $50 \%$ dan suhu antara $4-35^{\circ} \mathrm{C} .{ }^{25,26}$ Pinjal kucing tahap pradewasa ini dapat berkembangbiak dengan baik pada habitat dan inang yang sesuai. Keberadaan pinjal dapat diminimalisir dengan selalu menjaga kebersihan dan rutin melakukan perawatan pada kucing.

Informasi terkait infestasi pinjal dapat bermanfaat untuk mengetahui potensi pinjal dalam menularkan penyakit, salah satunya adalah Rickettsiosis. Di Kabupaten Banjarnegara belum dilaporkan kasus Rickettsiosis meskipun sudah ada penelitian yang melaporkan adanya pinjal $X$. cheopis dan 
Stivalius cognatus yang positif Rickettsia spp. di Kabupaten Banjarnegara. ${ }^{27}$ Dalam penelitian ini kucing dijadikan sebagai sampel penelitian karena merupakan salah satu hewan peliharaan yang digemari masyarakat sehingga memiliki kontak erat dengan manusia. Tujuan penelitian ini adalah memperoleh informasi infestasi pinjal pada kucing rumah dan mengidentifikasi faktor yang mempengaruhi keberadaan pinjal pada kucing. Informasi mengenai infestasi pinjal pada kucing dan faktor yang mempengaruhinya diperlukan sebagai kewaspadaan dini masyarakat terhadap penyakit tular pinjal di Kabupaten Banjarnegara mengingat adanya potensi penularan Rickettsiosis di Kabupaten Banjarnegara.

\section{METODE}

Penelitian ini merupakan penelitian observasional analitik dengan pendekatan cross-sectional. Lokasi penelitian yaitu tempat-tempat umum (pasar, rumah makan, dan kebun binatang) dan permukiman penduduk di Kabupaten Banjarnegara. Terdapat sepuluh desa/kelurahan dari lima kecamatan di Kabupaten Banjarnegara yang dijadikan sebagai lokasi survei. Waktu penelitian dilakukan mulai bulan JuniNovember 2019. Pelaksanaan penelitian ini telah mendapatkan persetujuan etik dari Komisi Etik Penelitian Kesehatan, Badan Litbang Kesehatan, Kemenkes RI Nomor LB.02.01/2/KE.204/2019.

Populasi dalam penelitian ini adalah semua kucing dan pemilik kucing di wilayah Kabupaten Banjarnegara. Sampel penelitian terdiri atas dua kelompok sampel, yaitu kelompok sampel kucing rumah $(F$. catus) baik liar maupun peliharaan dan kelompok sampel pemilik kucing peliharaan jenis kucing rumah. Kriteria inklusi untuk sampel kucing rumah adalah kucing dipelihara dan dirawat secara rutin atau tidak, kucing rumah yang hidup bebas/liar, usia dewasa (> 6 bulan). Jenis kucing selain kucing rumah tidak dijadikan sebagai sampel penelitian. Penentuan jumlah sampel kucing rumah dihitung menggunakan rumus Lemeshow untuk populasi yang tidak diketahui. ${ }^{28}$

$$
\begin{aligned}
\mathrm{n} & =\frac{\mathrm{z}_{1-\alpha / 2}^{2} \mathrm{P}(1-\mathrm{p})}{\mathrm{d}^{2}} \\
& =\frac{(1,960)^{2}(0,25)}{(0,10)^{2}} \\
& =96,04
\end{aligned}
$$

Keterangan :

$$
\begin{array}{ll}
\mathrm{n} & : \text { jumlah sampel } \\
\mathrm{Z}^{2}{ }_{1-\alpha / 2}: \begin{array}{l}
: \\
\text { nilai standar normal (jika } \alpha=0,05, \text { maka } \\
\end{array} & \mathrm{Z}=1,960) \\
\mathrm{P}(1-\mathrm{p}): \begin{array}{l}
\text { : estimasi proporsi populasi (jika } \mathrm{P}=0,5, \\
\text { maka } \mathrm{P}(1-\mathrm{p})=0,25)
\end{array} \\
\mathrm{d} \quad \text { : penyimpangan yang ditolerir }(10 \%)
\end{array}
$$

Besar sampel minimal yang diambil dalam penelitian ini adalah 100 ekor dengan jumlah sampel kucing yang dirawat 50 ekor dan jumlah sampel kucing tidak dirawat 50 ekor. Jumlah sampel pemilik kucing peliharaan yang dijadikan responden sejumlah 50 orang, sesuai dengan jumlah sampel kucing dengan kategori dirawat. Cara pengambilan sampel dilakukan dengan metode purposive sampling.

Pengumpulan data dilakukan dengan survei kucing dan wawancara. Penangkapan kucing liar dilakukan dengan cara memberi umpan dan memasukkannya ke dalam kandang. Cara lainnya yaitu menggunakan perangkap hidup yang diletakkan pada tempattempat umum (kebun binatang dan pasar). Sedangkan penangkapan kucing peliharaan dengan meminta bantuan pemilik kucing. Kucing yang ditangkap disisir untuk dicari pinjalnya. Pinjal dimasukkan dalam microtube yang berisi alkohol $70 \%$ untuk selanjutnya diidentifikasi spesies pinjalnya menggunakan kunci identifikasi "Pictorial Keys by Centers for Disease Control and Prevention (CDC)". Semua kucing yang telah disurvei ditandai menggunakan spidol tahan air pada kuping kucing agar tidak terjadi pengambilan sampel berulang. Wawancara terhadap pemilik kucing dilakukan dengan menggunakan kuesioner dengan pertanyaan terkait perawatan kucing yang meliputi informasi tentang jumlah kucing 
yang dipelihara, cara perawatan kucing yang meliputi kebiasaan kucing dikandangkan, pemakaian shampoo khusus kucing, frekuensi kucing dimandikan, dan pemberian obat kutu/pinjal.

Data yang diperoleh dianalisis secara deskriptif dan statistik menggunakan uji Mann-Whitney dan Chi-Square. Uji statistik dilakukan dengan uji Mann-Whitney karena data berdistribusi tidak normal.

\section{HASIL}

Dari kegiatan survei pinjal pada sampel kucing rumah diperoleh data jumlah sampel kucing rumah yang positif pinjal dan jumlah pinjal yang ditemukan. Berdasarkan Tabel 1 dapat dilihat bahwa persentase keberadaan pinjal pada kucing rumah yang dirawat lebih besar dibandingkan dengan kucing rumah yang tidak dirawat. Demikian juga untuk rerata pinjal yang ditemukan pada kategori kucing dirawat menunjukkan angka yang lebih besar daripada kategori kucing rumah yang tidak dirawat. Analisis perbedaan jumlah pinjal antara kelompok kucing dirawat dan tidak dirawat menggunakan uji MannWhitney karena distribusi data tidak normal. Berdasarkan hasil analisis statistik diperoleh nilai $\mathrm{p}=0,072$, artinya tidak ada perbedaan yang signifikan antara infestasi pinjal pada kucing yang dirawat dan tidak dirawat.

Tabel 1. Jumlah Pinjal pada Sampel Kucing Rumah di Kabupaten Banjarnegara Tahun 2019

\begin{tabular}{lcccccccc}
\hline $\begin{array}{l}\text { Kategori } \\
\text { Sampel } \\
\text { Kucing }\end{array}$ & $\begin{array}{c}\text { Jumlah } \\
\text { Sampel }\end{array}$ & $\begin{array}{c}\text { Jumlah } \\
\text { Sampel } \\
\text { Positif }\end{array}$ & $\begin{array}{c}\text { Persentase } \\
\text { Sampel } \\
\text { Positif }\end{array}$ & $\begin{array}{c}\text { Jumlah } \\
\text { Pinjal }\end{array}$ & $\begin{array}{c}\text { Rerata } \\
\text { Pinjal }\end{array}$ & $\begin{array}{c}\text { Nilai } \\
\text { Min- } \\
\text { Max }\end{array}$ & $\begin{array}{c}\text { Standar } \\
\text { Deviasi }\end{array}$ & $\begin{array}{c}\text { Hasil Uji } \\
\text { Mann- } \\
\text { Whitney }\end{array}$ \\
\hline Dirawat & 50 & 41 & $82 \%$ & 245 & 4,90 & $0-26$ & 5,003 & $\mathrm{p}=0,072$ \\
$\begin{array}{l}\text { Tidak } \\
\text { dirawat }\end{array}$ & 50 & 34 & $68 \%$ & 229 & 4,58 & $0-32$ & 7,659 & \\
\hline Total & 100 & 75 & $75 \%$ & 474 & 4,74 & $0-32$ & 6,438 &
\end{tabular}

Hasil identifikasi pinjal terhadap sampel pinjal yang ditemukan pada kucing rumah menunjukkan spesies pinjal yang dominan adalah C. felis $(99,8 \%)$. Spesies

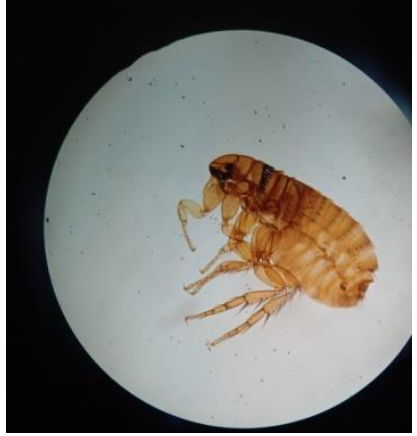

(i) lainnya yaitu $X$. cheopis $(0,2 \%)$ yang ditemukan dari kategori kucing rumah tidak dirawat dan berasal dari lokasi survei kebun binatang.

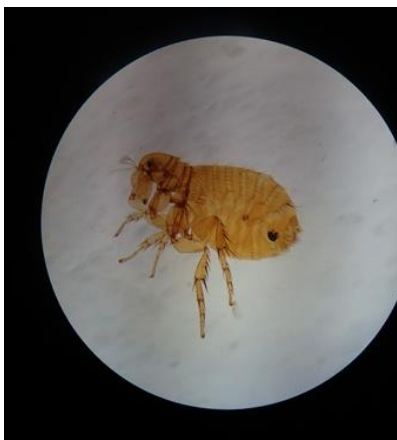

(ii)

Gambar 2. Ctenocephalides felis (i); Xenopsylla cheopis (ii) 
Hubungan Infestasi Pinjal pada Kucing yang Dirawat dengan Perawatan Kucing

Infestasi pinjal pada kucing dapat dipengaruhi oleh perawatan yang diberikan pada kucing. Pada penelitian ini pola perawatan kucing yang dikaitkan dengan infestasi pinjal yaitu jumlah kucing yang dipelihara, kebiasaan kucing dikandangkan, frekuensi kucing dimandikan menggunakan shampoo khusus kucing, dan pemberian obat kutu/pinjal. Hasil uji Chi-Square pola perawatan kucing rumah terhadap keberadaan pinjal di Kabupaten Banjarnegara disajikan seperti pada Tabel 2.

Tabel 2. Hasil Uji Chi-Square Pola Perawatan Kucing Rumah terhadap Keberadaan Pinjal di Kabupaten Banjarnegara Tahun 2019

\begin{tabular}{|c|c|c|c|c|}
\hline \multirow{2}{*}{ Pola Perawatan Kucing } & \multicolumn{2}{|c|}{ Keberadaan Pinjal } & \multirow[t]{2}{*}{ Total } & \multirow{2}{*}{$\begin{array}{c}\text { Hasil Uji } \\
\text { Chi-Square }\end{array}$} \\
\hline & Ada & Tidak & & \\
\hline \multicolumn{5}{|l|}{ Jumlah Kucing Dipelihara: } \\
\hline 1 ekor & $3(75 \%)$ & $1(25 \%)$ & $4(100 \%)$ & $p=0,884$ \\
\hline 2-10 ekor & $26(83,9 \%)$ & $5(16,1 \%)$ & $31(100 \%)$ & \\
\hline$>10$ ekor & $12(80 \%)$ & $3(20 \%)$ & $15(100 \%)$ & \\
\hline Total & $41(82 \%)$ & $9(18 \%)$ & $50(100 \%)$ & \\
\hline \multicolumn{5}{|l|}{$\begin{array}{l}\text { Kebiasaan Kucing } \\
\text { Dikandangkan: }\end{array}$} \\
\hline Ya & $21(87,5 \%)$ & $3(12,5 \%)$ & $24(100 \%)$ & $p=0,331$ \\
\hline Tidak & $20(76,9 \%)$ & $6(23,1 \%)$ & $26(100 \%)$ & \\
\hline Total & $41(82 \%)$ & $9(18 \%)$ & $50(100 \%)$ & \\
\hline \multirow{2}{*}{\multicolumn{5}{|c|}{$\begin{array}{l}\text { Frekuensi Kucing } \\
\text { Dimandikan Menggunakan } \\
\text { Shampoo Khusus Kucing: }\end{array}$}} \\
\hline & & & & \\
\hline 2 minggu & $0(0 \%)$ & $3(100 \%)$ & $3(100 \%)$ & $p=0,001$ \\
\hline 4 minggu & $18(85,7 \%)$ & $3(14,3 \%)$ & $21(100 \%)$ & \\
\hline Total & $18(75 \%)$ & $6(25 \%)$ & $24(100 \%)$ & \\
\hline \multicolumn{5}{|l|}{ Pemberian Obat Kutu/Pinjal: } \\
\hline Ya & $13(72,2 \%)$ & $5(27,8 \%)$ & $18(100 \%)$ & $\mathrm{p}=0,177$ \\
\hline Tidak & $28(87,5 \%)$ & $4(12,5 \%)$ & $32(100 \%)$ & \\
\hline Total & $41(82 \%)$ & $9(18 \%)$ & $50(100 \%)$ & \\
\hline
\end{tabular}

Persentase keberadaan pinjal pada kucing berdasarkan pola perawatan kucing dapat dilihat pada Tabel 2. Kucing yang dipelihara dalam satu rumah yang jumlahnya 
lebih dari satu ekor mempunyai persentase keberadaan pinjal yang lebih besar dibandingkan dengan jumlah kucing yang hanya satu ekor dalam satu rumah. Akan tetapi, uji Chi-Square menunjukkan bahwa tidak ada hubungan yang signifikan antara jumlah kucing dipelihara dengan keberadaan pinjal (nilai $\mathrm{p}=0,884$ ).

Keberadaan pinjal pada kucing yang biasa dikandang dan tidak dikandang memiliki angka yang tidak jauh berbeda. Berdasarkan uji Chi-Square terlihat bahwa tidak ada hubungan yang signifikan antara kebiasaan kucing dikandangkan dengan keberadaan pinjal (nilai $\mathrm{p}=0,331$ ).

Kucing yang dimandikan menggunakan shampoo khusus kucing secara rutin dua minggu sekali tidak ditemukan adanya pinjal. Pada kucing yang dimandikan empat minggu sekali masih ditemukan adanya pinjal. Uji statistik menggunakan uji ChiSquare menunjukkan bahwa ada hubungan yang signifikan antara frekuensi kucing dimandikan menggunakan shampoo khusus kucing dengan keberadaan pinjal (nilai $\mathrm{p}=$ 0,001).

Dari Tabel 2 dapat dilihat bahwa kucing yang diberi obat kutu/pinjal masih ditemukan adanya pinjal yaitu sebesar 72,2\% . Namun, persentase keberadaan pinjal pada kucing yang tidak diberi obat kutu/pinjal lebih besar daripada kucing yang diberi obat kutu/pinjal. Berdasarkan uji Chi-Square dapat disimpulkan bahwa tidak ada hubungan yang signifikan antara pemberian obat kutu/pinjal dengan keberadaan pinjal (nilai $p=0,177$ ).

\section{PEMBAHASAN}

Keberadaan pinjal dapat menyebabkan gangguan kesehatan pada manusia dan hewan. Keberadaan pinjal yang mengandung Rickettsia menjadi faktor risiko penularan Rickettsiosis. ${ }^{17}$ Indeks pinjal dapat dijadikan sebagai salah satu indikator yang digunakan untuk menentukan status kerawanan penyakit di suatu daerah. Namun, saat ini belum ada indikator status kerawanan untuk penyakit Rickettsiosis. Oleh karena itu, dalam penelitian ini belum bisa ditentukan apakah Kabupaten Banjarnegara merupakan daerah rawan Rickettsiosis berdasarkan angka indeks pinjal yang diperoleh.

Kasus Rickettsiosis di Indonesia belum banyak terlaporkan karena masih terbatasnya skrining untuk Rickettsiosis. Penelitian Lokida et al menyebutkan dari 975 sampel pasien rawat inap yang dinyatakan negatif Demam Berdarah Dengue setelah dilakukan pemeriksaan Rickettsia dengan ELISA ditemukan sebanyak 103 (10,6\%) positif Rickettsia. ${ }^{29}$ Kesalahan diagnosis penyakit dapat terjadi karena penyakit ini mempunyai gejala yang bersifat tidak spesifik, sehingga menyebabkan penanganan penyakit yang kurang tepat. Tes diagnosis yang cepat, akurat dan murah diperlukan untuk mendukung diagnosis penyakit. ${ }^{30}$

Laporan kasus Rickettsiosis di Kabupaten Banjarnegara juga masih sangat terbatas. Sampai saat ini Rickettsiosis belum menjadi prioritas program di Kabupaten Banjarnegara. Dengan adanya penelitian sebelumnya oleh Pramestuti tahun 2017 yang melaporkan adanya Rickettsia spp. pada pinjal yang dikoleksi dari tikus di wilayah Kabupaten Banjarnegara, menunjukkan adanya potensi penularan Rickettsiosis di Kabupaten Banjarnegara. Untuk itu kewaspadaan dini masyarakat terhadap penyakit tular pinjal perlu ditingkatkan agar meminimalisir adanya penularan penyakit. Data mengenai pinjal pada hewan terutama hewan peliharaan yang hubungannya erat dengan manusia penting untuk digunakan sebagai pertimbangan dalam tindakan pengendalian penyakit tular pinjal di masyarakat.

Survei pinjal pada sampel kucing rumah yang dilakukan di Kabupaten Banjarnegara memberikan hasil bahwa kucing yang positif pinjal sebagian besar merupakan kucing yang sudah mendapatkan perawatan yang baik oleh pemiliknya. Hal ini dilihat dari persentase kucing positif pinjal yang lebih banyak ditemukan pada kategori kucing rumah yang dirawat. Selain itu jumlah pinjal antara kelompok kucing dirawat dan tidak dirawat 
tidak menunjukkan adanya perbedaan secara statistik, artinya kelompok kucing yang dirawat dengan baik mempunyai jumlah pinjal sama banyaknya dengan kelompok kucing tidak dirawat. Hal ini menunjukkan bahwa kucing yang dirawat dengan baik secara rutin belum tentu bersih dari pinjal. Ditemukannya pinjal pada hewan peliharaan khususnya kucing menunjukkan potensi kucing dalam menularkan penyakit tular pinjal ke manusia.

Perawatan kucing peliharaan dapat mencegah adanya pinjal pada kucing. Alternatif perawatan kucing yang banyak dilakukan untuk menghilangkan pinjal pada kucing yaitu dengan membawa kucing peliharaan ke pet shop untuk dilakukan grooming. Namun, secara alamiah kucing memiliki kebiasaan melakukan oral grooming atau self grooming. Kucing rumah biasanya menghabiskan waktu untuk melakukan oral grooming sekitar $8 \%$ dari waktu istirahatnya. Oral grooming terbukti efektif dapat menghilangkan pinjal pada kucing. ${ }^{31}$ Kucing rumah lebih banyak menghabiskan waktu untuk melakukan self grooming $(9,66 \%)$ dibandingkan kucing liar $(5,75 \%))^{32}$ Oleh karena itu kucing liar maupun kucing peliharaan yang tidak dirawat tidak selalu terinfestasi pinjal karena melakukan oral grooming yang dapat meminimalisir adanya pinjal.

Hasil penelitian menunjukkan bahwa 99,8\% pinjal yang ditemukan yaitu C. felis. Ctenocephalides felis merupakan jenis pinjal yang paling banyak dijumpai pada kucing rumah. ${ }^{25}$ Penelitian Cruz-Vazquez et al di Cuernavaca, Mexico mengemukakan bahwa sebanyak 517 kucing yang telah ditangkap terdapat $92,3 \%$ kucing yang hanya terinfestasi C. felis dan $7,7 \%$ terinfestasi $C$. felis dan $C$. canis. ${ }^{33}$ Penelitian Chandra et al di New Zealand menunjukkan 98,7\% (228/231) pinjal yang dikumpulkan dari 25 kucing dan 22 anjing adalah $C$. felis. ${ }^{34}$ Penelitian Xhaxiu et al di Albania menyatakan bahwa ektoparasit yang diidentifikasi pada 26 kucing semuanya merupakan C. felis (100\%). ${ }^{35}$ Penelitian lainnya oleh Thomas et al tahun 2016 juga melaporkan hasil identifikasi pinjal pada 323 ekor kucing domestik ditemukan sebanyak 313 ekor diantaranya terinfeksi C. felis $(97,2 \%){ }^{8}$ Hasil penelitian sejenis oleh Bashofi et al di lingkungan kampus Institusi Pertanian Bogor menunjukkan C. felis sebagai spesies pinjal dominan yang ditemukan pada 30 ekor kucing. Penelitian Siagian dan Fikri di Bogor juga menunjukkan jenis pinjal yang menginfestasi kucing di klinik hewan di Kabupaten Bogor adalah $C$. felis. ${ }^{24}$

Selain $C$. felis terdapat jenis pinjal lain yang ditemukan yaitu $X$. cheopis yang biasanya dijumpai pada tikus. Infestasi pinjal dapat ditularkan oleh hewan satu ke hewan yang lain apabila hewan tersebut merupakan inang pinjal yang mempunyai habitat mikro sesuai untuk pinjal bertahan hidup. ${ }^{26}$ Xenopsylla cheopis merupakan vektor utama penyakit pes dan murine thypus. ${ }^{36,37}$ Penelitian Jiang et al di Malang, Jawa Timur melaporkan R. felis terdeteksi pada X. cheopis. ${ }^{37}$ Menurut hasil dari beberapa penelitian yang telah dilakukan selama ini $R$. felis ditemukan pada C. felis. ${ }^{19,34}$ Hal ini menunjukkan bahwa $X$. cheopis juga dapat menularkan penyakit yang diakibatkan oleh $R$. felis yaitu flea borne spotted fever (cat flea thypus).

Hasil penelitian menunjukkan kucing peliharaan yang biasa dikandang masih dijumpai adanya pinjal. Berdasarkan uji statistik diketahui tidak ada hubungan yang signifikan antara kebiasaan kucing dikandangkan dengan keberadaan pinjal. Hal ini dapat dikaitkan dengan jumlah kucing yang dipelihara dalam satu rumah. Walaupun kucing dikandangkan, tapi jika dalam satu rumah terdapat kucing dalam jumlah banyak akan meningkatkan risiko kucing terinfestasi pinjal dari kucing lainnya. Menurut penelitian Beugnet et al tahun 2012-2013 menyatakan bahwa infestasi pinjal antara kucing yang dipelihara secara tunggal dan kucing yang dipelihara dengan jumlah lebih dari satu ekor tidak berbeda secara signifikan $(\mathrm{OR}=1,25$; CI $=0,64-2,36)$. Namun, kucing yang dipelihara secara tunggal mempunyai risiko rendah terinfestasi pinjal $(\mathrm{OR}=0,40 ; \mathrm{CI}=0,17$ - 
0,92). ${ }^{38}$ Hal ini sesuai dengan data hasil penelitian yang menyebutkan bahwa kucing peliharaan yang jumlahnya lebih dari satu ekor memiliki persentase keberadaan pinjal lebih besar, namun secara statistik tidak berhubungan jumlah kucing dipelihara dengan keberadaan pinjal.

Kucing peliharaan yang tidak dikandang dan dibiarkan bermain di luar rumah juga memiliki peluang yang besar terinfestasi pinjal dari lingkungan sekitar. Kucing kampung liar yang hidup bersamasama dengan kucing peliharaan dapat menularkan ektoparasit pada kucing peliharaan. ${ }^{8}$ Jadi walaupun kucing peliharaan sudah dirawat dengan baik dengan dimandikan rutin dan diberi obat penghilang kutu atau pinjal, masih ada kemungkinan untuk tertular pinjal dari lingkungan. Lingkungan rumah dan pekarangan dapat menjadi sumber terjadinya reinfestasi pinjal. ${ }^{11}$

Kucing lebih berisiko terinfestasi pinjal jika perawatannya tidak menggunakan shampoo khusus kucing. Terdapat sekitar 52\% kucing yang perawatannya hanya menggunakan shampoo biasa, bukan shampoo khusus kucing. Penggunaan shampoo biasa kurang efektif dalam menghilangkan pinjal pada kucing. Seringkali pinjal akan kembali lagi ke tubuh kucing setelah kucing selesai dimandikan.

Pemakaian shampoo khusus kucing dapat mengurangi adanya pinjal pada kucing karena mengandung bahan aktif sebagai racun yang dapat membunuh pinjal. Beberapa bahan aktif yang terkandung dalam shampoo khusus kucing yaitu deltamethrin, cypermethrin, pyrethrin. ${ }^{39}$ Penelitian penggunaan shampoo dengan bahan aktif deltamethrin pada anjing dapat membunuh $100 \%$ pinjal $C$. felis dewasa setelah pemakaian 24 jam, perlindungan > 98\% pada minggu kedua, dan $>95 \%$ pada minggu ketiga. ${ }^{25,40}$ Hal tersebut sesuai dengan hasil penelitian yang menunjukkan bahwa ada hubungan frekuensi kucing dimandikan menggunakan shampoo khusus kucing dengan keberadaan pinjal. Penggunaan shampoo khusus kucing dua minggu sekali mampu mengurangi keberadaan pinjal pada kucing.

Pemakaian obat anti pinjal juga dapat dijadikan alternatif untuk mengurangi keberadaan pinjal pada kucing. Contoh obat anti pinjal yang biasa digunakan yaitu fluralaner, obat ini dapat melindungi hewan peliharaan dari gangguan pinjal dengan pengulangan pemakaian setiap tiga bulan. ${ }^{41}$ Penggunaan kalung anti pinjal yang mengandung bahan aktif imidacloprid/ flumethrin juga dinilai efektif dalam menghilangkan pinjal dalam waktu 8 bulan. ${ }^{25}$ Namun, hasil penelitian ini tidak menunjukkan adanya hubungan antara pemberian obat pinjal dengan keberadaan pinjal.

\section{KESIMPULAN}

Pinjal lebih banyak ditemukan pada kucing rumah yang dipelihara daripada kucing yang hidup liar. Infestasi pinjal pada kucing rumah berhubungan dengan frekuensi kucing yang dimandikan dengan menggunakan shampoo khusus kucing.

\section{SARAN}

Agar kucing peliharaan terhindar dari pinjal, sebaiknya selalu menjaga kebersihan kucing peliharaan dengan melakukan perawatan secara rutin yaitu dengan memandikan kucing maksimal dua minggu sekali dengan menggunakan shampoo khusus kucing.

\section{UCAPAN TERIMA KASIH}

Penulis mengucapkan terima kasih kepada Kepala Balai Litbang Kesehatan Banjarnegara; Bapak Anorital, SKM, M.Kes yang memberikan masukan dalam penyusunan protokol penelitian dan penyelesaian laporan penelitian; Nova Pramestuti, SKM, M.Sc yang memberi masukan dalam penyusunan naskah publikasi; peneliti dan teknisi Balai Litbang Kesehatan Banjarnegara yang telah membantu pelaksanaan pengumpulan data penelitian; Lurah/Kepala Desa di wilayah penelitian; serta responden yang bersedia berpartisipasi dalam kegiatan penelitian. 


\section{KONTRIBUTOR PENULIS}

EL sebagai kontributor utama bertanggung jawab dalam hal pembuatan draf naskah publikasi, pembahasan, analisis data, revisi dan mengedit artikel. $\mathrm{R}$ dan DPN sebagai kontributor anggota bertanggung jawab dalam membantu dalam merevisi dan mengedit artikel.

\section{DAFTAR PUSTAKA}

1. Sigit SH, Koesharto FX, Hadi UK, Gunandini DJ, Soviana S, Wirawan IA. Hama pemukiman Indonesia. Sigit SH, Hadi UK, editor. Bogor: Unit Kajian Pengendalian Hama Permukiman; 2006. 116 p.

2. Oguge NO, Durden LA, Keirans JE, Balami HD, Schwan TG. Ectoparasites (sucking lice, fleas and ticks) of small mammals in southeastern Kenya. Med Vet Entomol. 2009;23:387-92.

3. Santoso L. Pengantar entomologi kesehatan masyarakat. Jilid II. Semarang: Bagian Epidemiologi dan Penyakit Tropik FKM UNDIP; 1997.

4. Bitam I, Dittmar K, Parola P, Whiting MF, Raoult D. Fleas and flea-borne diseases. Int J Infect Dis. 2010;14(8):e667-76. doi:10.1016/j.ijid.2009.11.011.

5. Dobler G, Pfeffer M. Fleas as parasites of the family Canidae. Parasit Vectors. 2011;4(139):1-12. doi:10.1186/1756-3305-4139.

6. Traversa D. Fleas infesting pets in the era of emerging extra-intestinal nematodes. Parasit Vectors. 2013;6(59):1-15.

7. Lawrence AL, Hii SF, Jirsová D, Panakova L, Ionica AM, Gilchrist $\mathrm{K}$, et al. Integrated morphological and molecular identification of cat fleas (Ctenocephalides felis) and dog fleas (Ctenocephalides canis) vectoring Rickettsia felis in central Europe. Vet Parasitol. 2015;210(3-4):215-23.

doi:10.1016/j.vetpar.2015.03.029.

8. Thomas JE, Staubus L, Goolsby JL, Reichard MV. Ectoparasites of free-roaming domestic cats in the central United States. Vet Parasitol. 2016;228:17-22.

doi:10.1016/j.vetpar.2016.07.034.

9. Bashofi A, Soviana S, Ridwan Y. Infestasi pinjal dan infeksi Dipylidium caninum
(Linnaeus) pada kucing liar di lingkungan kampus Institut Pertanian Bogor, Kecamatan Dramaga. J Entomol Indones. 2015;12(2):10814. doi:10.5994/jei.12.2.108.

10. Maina AN, Fogarty C, Krueger L, Macaluso KR, Odhiambo A, Nguyen K, et al. Rickettsial infections among Ctenocephalides felis and host animals during a flea-borne rickettsioses outbreak in Orange County, California. PLoS One. 2016;11(8):1-13. doi:10.1371/journal.pone.0160604.

11. Youssefi MR, Rahimi MT. Extreme human annoyance caused by Ctenocephalides felis felis (cat flea). Asian Pac J Trop Biomed. 2014;4(4):334-6. doi:10.12980/APJTB.4.2014C795.

12. Jan Š, Lawrence A, Reichel MP. Cat fleas (Ctenocephalides felis) carrying Rickettsia felis and Bartonella species in Hong Kong. Parasitol Int. 2018;67:209-12. doi:10.1016/j.parint.2017.12.001.

13. Ristiyanto, Handayani FD, Boewono DT, Heriyanto B. Penyakit tular rodensia. Yogyakarta: Gadjah Mada University Press; 2014.

14. Widjaja S, Williams M, Winoto I, Farzeli A, Stoops CA, Barbara KA, et al. Geographical assessment of Rickettsiosis in Indonesia. Vector-Borne Zoonotic Dis. 2016;16(1):20-5. doi:10.1089/vbz.2015.1840.

15. Richards AL, Soeatmadji DW, Widodo MA, Sardjono TW, Yanuwiadi B, Hernowati TE, et al. Seroepidemiologic evidence for murine and scrub typhus in Malang, Indonesia. Am J Trop Med Hyg. 1997;57(1):91-5.

16. Dennis DT, Hadi TR, Brown RJ, Sukaeri S, Leksana B, Cholid R. A survey of scrub and murine typhus in the Ancol section of Jakarta, Indonesia. Southeast Asian J Trop Med Public Heal. 1981;12(4):574-80.

17. Widiastuti D, Trisnawati UF, Pramestuti N. Deteksi Rickettsia spp. pada pinjal tikus di Kota Semarang. Balaba. 2018;14(2):127-34.

18. Aung AK, Spelman DW, Murray RJ, Graves S. Review Article: Rickettsial infections in Southeast Asia: Implications for local populace and febrile returned travelers. Am J Trop Med Hyg. 2014;91(3):451-60. doi:10.4269/ajtmh.14-0191.

19. Capelli G, Montarsi F, Porcellato E, Maioli G, 
Furnari C, Rinaldi L, et al. Occurence of Rickettsia felis in dog and cat fleas (Ctenocephalides felis) from Italy. Parasit Vectors. 2009;2(Suppl 1):S8. doi:10.1186/1756-3305-2-S1-S8.

20. Kramer F, Mencke N. General morphology. In: Flea biology and control. Berlin: SpringerVerlag; 2001:3-4.

21. Beck W, Boch K, Mackensen H, Wiegand B, Pfister K. Qualitative and quantitative observations on the flea population dynamics of dogs and cats in several areas of Germany. Vet Parasitol. 2006;137:130-36. doi:10.1016/j.vetpar.2005.12.021.

22. CDC. Pictorial Keys: Arthropods, reptiles, birds, and mammals of public health significance. Georgia: Centers for Disease Control and Prevention of the U. S. Public Health Service; 2000.

23. Nasution AYA. Kajian parasitosis pada anjing dan kucing peliharaan yang datang ke klinik hewan di Jakarta Utara [Tesis]. Bogor: Institut Pertanian Bogor; 2018.

24. Siagian TB, Fikri FH. Infestasi ektoparasit pada kucing di klinik hewan Kabupaten Bogor. Prosiding Seminar Nasional Teknologi Terapan Inovasi Dan Rekayasa (SNT2IR) 2019; 1 Desember 2019; Kendari: Universitas Halu Oleo; 2019. p480-4.

25. Rust MK. The biology and ecology of cat fleas and advancements in their pest management : a review. Insects. 2017;8(118):1-49. doi:10.3390/insects8040118.

26. Rust MK. Advances in the control of Ctenocephalides felis (cat flea) on cats and dogs. Trends Parasitol. 2005;21(5):232-6. doi:10.1016/j.pt.2005.03.010.

27. Pramestuti N, Umniyati SR, Mulyaningsih B, Widiastuti D, Raharjo J. Evidence of Rickettsia typhi in rat fleas of various habitat and the potential transmission of murine typhus in Banjarnegara, Central Java, Indonesia. Indian J Public Heal Res Dev. 2018;9(8):1548-53.

28. Lemeshow S, Hosmer DW, Klar J, Lwanga SK. Adequacy of sample size in health studies. New York: John Wiley \& Sons; 1990.

29. Lokida D, Hadi U, Lau C, Kosasih H, Liang CJ, Rusli M, et al. Underdiagnoses of Rickettsia in patients hospitalized with acute fever in Indonesia: observational study results.
BMC Infect Dis. 2020;20(364):1-12.

30. Gasem MH, Wagenaar JFP, Goris MGA, Adi MS, Isbandrio BB, Hartskeerl, et al. Murine typhus and leptospirosis as causes of acute undifferentiated fever, Indonesia. Emerg Infect Dis. 2009;15(6):975-8. doi:10.3201/eid1506.081405.

31. Eckstein RA, Hart BL. Grooming and control of fleas in cats. Appl Anim Behav Sci. 2000;68(January):141-50. doi:10.1016/S01681591(00)00095-2.

32. Berteselli GV, Regaiolli B, Normando S, Mori B De, Zaborra CA, Spiezio C. European wildcat and domestic cat: do they really differ? J Vet $\quad$ Behav. 2017. doi:10.1016/j.jveb.2017.09.006.

33. Cruz-vazquez C, Gamez EC, Fernandez MP, Parra MR. Seasonal occurrence of Ctenocephalides felis felis and Ctenocephalides canis (Siphonaptera: Pulicidae) infesting dogs and cats in an urban area in Cuernavaca, Mexico. J Med Entomol. 2001;38(1):111-3.

34. Chandra S, Forsyth M, Lawrence AL, Emery D, Slapeta J. Cat fleas (Ctenocephalides felis) from cats and dogs in New Zealand: Molecular characterisation, presence of Rickettsia felis and Bartonella clarridgeiae and comparison with Australia. Vet Parasitol. 2017;234:25-30. doi:10.1016/j.vetpar.2016.12.017.

35. Xhaxhiu D, Kusi I, Rapti D, Visser M, Knaus M, Lindner T, et al. Ectoparasites of dogs and cats in Albania. Patasitol Res. 2009;105(6):1577-87. doi:10.1007/s00436009-1591-X.

36. Eisen RJ, Gage KL. Transmission of fleaborne zoonotic agents. Annu Rev Entomol. 2012;57:61-82. doi:10.1146/annurev-ento120710-100717.

37. Jiang J, Soeatmadji DW, Henry KM, Ratiwayanto S, Bangs MJ, Richards AL. Rickettsia felis in Xenopsylla cheopis, Java, Indonesia. Emerg Infect Dis. 2006;12(8):12813.

38. Beugnet F, Bourdeau P, Chalvet-monfray K, Cosma V, Farkas R, Guillot J, et al. Parasites of domestic owned cats in Europe: coinfestations and risk factors. Parasit Vectors. 2014;7(291):1-13. doi: 10.1186/1756-3305-7291. 
Hubungan Infestasi........(Lestari, dkk)

39. Maddison J, Page S, Church D. Small animal clinical pharmacology. Elsevier; 2008.

40. Franc M, Cadiergues MC. Activity of a deltamethrin shampoo against Ctenocephalides felis and Rhipicephalus sanguineus in dogs. Vet Parasitol. 1999;81:341-6.

41. Taenzler J, Gale B, Zschiesche E, Roepke RKA, Heckeroth AR. The effect of water and shampooing on the efficacy of fluralaner spoton solution against Ixodes ricinus and Ctenocephalides felis infestations in dogs. Parasit Vectors. 2016;9(233):1-5. doi:10.1186/s13071-016-1367-y. 
BALABA Vol. 16 No. 2, Desember 2020: 123-134 